\title{
Los conceptos de arqueología e historia del arte antiguo y medieval: apuntes historiográficos
}

\author{
OdILE RIPOLL LÓPEZ* \\ GISELA RIPOLL LOPEZ ** \\ «A determinada altura todo coincide \\ y se identifica: las ideas del filósofo, las \\ obras del artista y las buenas accio- \\ nes".
}

FRIEDRICH NIETZSCHE

La actual preocupación de las nuevas generaciones de historiadores, al igual que ocurrió con las precedentes, es que son herederas de un pasado científico de gran envergadura '. Así lo expresó ya $\mathrm{H}$. Stuart Hughes: "La mayoría de nosotros nos hallábamos oprimidos por la sensación de que el trabajo más importante ya había sido realizado; los documentos ya habian sido analizados y también estaba establecido el canon para su interpretación. Nos considerábamos epígonos trabajando a la sombra de los grandes historiadores de las generaciones que nos precedieron ${ }^{2}$ ". Pero el campo de estudio es amplio y las posibilidades ilimitadas en el

* Universidad Autónoma de Barcelona.

** Departamento de Prehistoria e Historia Antigua, UNED, Madrid.

- Agradecemos a los Profesores Xavier Barral i Altet y Jesús Viñuales sus valiosas sugerencias. Muchas ideas del Prof. Barral están reunidas en la entrevista realizada por Gisela Ripoll para Revista de Arqueología, año V, n. ${ }^{\circ} 40$, agosto 1984, págs. 9-13.

${ }^{2} \mathrm{H}$. StuARt Hughes: La historia como arte y como ciencia, 1964 (edición española de Aguilar, Madrid, 1967), pág. 31. 
momento de hacer nuevos planteamientos. Este es el caso de las páginas que siguen, que pretenden incidir sobre los problemas de la antigüedad clásica y el medioevo según la historia del arte y la arqueología.

Con el nacimiento del concepto de historia del arte como disciplina a partir del siglo $\mathrm{xVI}$ - su evolución tanto en el tratamiento como en la visión- junto al floreciente interés que surge en el siglo XVIII por la arqueologia ha hecho que las mutaciones en estos campos sean hoy motivo de reflexión. En este trabajo quisiéramos plantear sucintamente lo que significan ambos términos y cómo poco a poco forman una simbiósis $^{3}$. Esta es tal, que no se puede hablar ya de estudios diacrónicos, sino de un proceso histórico sincrónico que tiende al estudio global de las manifestaciones, fenómenos y modos de vivir humanos, tanto de la antigüedad como del medioevo.

Nos centraremos principalmente en lo sucedido desde mediados del siglo XVIII hasta las primeras décadas del siglo xx, pues como se verá, fue durante este período de tiempo cuando se configuraron esencialmente los actuales conceptos no sólo de las incipientes ciencias como la historia del arte y la arqueología, sino también de lo que se ha dado en denominar "historia total» o «nueva historia».

La preocupación por todos estos problemas surge ya entre los estudiosos hispánicos con Luis Vives, que, como señala J. Ortega y Gasset, fue uno de los principales humanistas que valoró el concepto de cultura: «El concepto y la palabra cultura, como ocupación del hombre con las letras, las artes, la filosofía, las ciencias, surgió en el humanismo y fue el humanista español Luis Vives el primero que metaforiza el cultivo del

\footnotetext{
${ }^{3}$ Existen varias recopilaciones que son interesantes como guias para introducirse en la labor de definir ambos conceptos y su modo de tratarlos, veánse por ejemplo: $H$. BAUER: Historiografia del Arte. Introducción crítica al estudio de la Historia del Arte, 1976, traducción española en Ed. Taurus, Madrid, 1980. Algunos problemas sobre historiadores del arte y diferentes escuelas quedan muy bien reflejados en J. VINUALES: El comentario de la Obra de Arte (Metodologias concretas), UNED, Aula Abierta, 12, Madrid, 1986 (en adelante nos referiremos a esta obra como El comentario...). Es orientativo también el volumen de: $F$. Checa, M. de los Santos y J. M. Moran: Guía para el estudio de la Historia del Arte, Madrid, Ed. Cátedra, 1987. Un estudio sugerente es el de E. JARDI: Otro Laoconte. Reflexiones sobre los limites de las artes plásticas, Madrid, Ed. Aguilar, 1968. Para el campo de la arqueologia, consúltense: G. DANIEL: Historia de la Arqueologia. De los anticuarios a V. Gordon Childe, 1967, versión castellana en Alianza Ed., Madrid, 1974. V. Gordon CHILDE: Introducción a la Arqueología, 1956, traducción castellana en Ed. Ariel, Barcelona, 1977. B. G. TRIEgGer: La revolución arqueológica. La obra de Gordon Childe, 1980, edición en castellano Ed. Fontamara, Barcelona, 1982.
} 
campo o agricultura para decir 'cultura animi'" ${ }^{4}$. Pero en todo caso los primeros estudios de historia del arte, según el concepto moderno, aparecen con Giorgio Vasari (1511-1574) en su obra Vidas de los más excelentes pintores, escultores $y$ arquitectos, donde, junto a las notas biográficas, presenta un catálogo de obras de arte, precedido de una introducción sobre las técnicas.

A lo largo del siglo XVII estos estudios se irán perfeccionando y determinando, pero la verdadera definición de historia del arte como ciencia - aunque también esto hoy se pone en duda- no llegará hasta la primera mitad del siglo XVIII con J. J. Winckelmann (1717-1768) ${ }^{5}$. Poeta, coleccionista, crítico de arte y gran erudito, Winckelmann revalorizó el interés por las culturas del mundo antiguo. Con su idea museística de la antigüedad, sus "galerias de estatuas» y su obra Historia del Arte en la Antigüedad $(1764)^{6}$, propuso unos preceptos básicos, pero no metodoló-

${ }^{4}$ J. Ortega y Gasset: Vives-Goethe, Madrid, Ediciones de la Revista de Occidente, 1973, pág. 153. En lo que se refiere a estudios sobre la cultura del periodo humanista y posterior de la ilustración se puede consultar como obra reciente: A. MESTRE: Influjo europeo y herencia hispánica. Mayans y la ilustración valenciana, Publicaciones del Ayuntamiento de Oliva, Serie Menor, VI, Valencia 1987, y también: Id., Despotismo e ilustración en España, Barcelona, 1976. Sobre personajes tan válidos como Ambrosio de Morales y Enrique Flórez, existen varias biografias que recogimos en: G. RIPOLL: "Historiografía y numismática visigodas entre los siglos XVI y XVII: Ambrosio de Morales y Enrique Flórez", Archéologie Aujourd'hui, n. 2 (Les mérovingiens. Archéologie et historiographie), Paris, 1989, págs. 58 64.

${ }^{5}$ Algunas de las obras que se pueden consultar sobre J. J. Winckelmann son las siguientes: L. CURTIUs (et alii): Johan Joachim Winckelmann. 1768/1968, Bad Godesberg, Inter Nationes, 1968. E. M. AgulLera: Prólogo a la Historia del Arte en la Antigüedad de J. J. Winckelmann, Ed. Iberia, Barcelona, 1984, págs. VII-XII. Der Grosse Brockhaus, Leipzig 1935, voz: Winckelmann, págs. 354-355. A. BuRgulere: Dictionnaire de Sciences Historiques, Presses Universitaires de France, Paris, 1986, voz: Art (Historire de l'), pág. 71 (en adelante nos referiremos a esta obra como Dictionnaire...). C. W. CERAM: "Winckelmann o el nacimiento de una ciencia", en Dioses, tumbas y sabios, Ediciones Destino, Barcelona, 10. edición de 1966, págs. 28-32. La bibliografía y citas sobre J. J. Winckelmann, son abundantísimas pero entre ellas cabe destacar la introducción y las notas realizadas por LEON MIS a la obra Gedanken über die Nachahmung der griechischen Werke in der Malerei und Bildhauerkunst (1755), publicada con el título Réflexions sur límitation des oeuvres grecques en peinture et en sculpture, Aubier Ed. Montaigne, Collection Bilingüe des Classiques Etrangers, Paris, 1954, págs. 5-84 (existe traducción castellana). R. BIANCHI BANDINELLI: Introducción a la arqueología clásica como historia del arte antiguo, 1976, edición castellana en Akal Ed., Madrid, 1982, págs. 41-64. En este último volumen citado, Bianchi hace una aproximación magistral a los problemas de historia del arte-arqueologia, especialmente sobre Winckelmann. O. RiPOLL: "El bicentenario de J. J. Winckelmann", Ampurias, XXX, Barcelona, 1968, págs. 369-371.

${ }^{6}$ Algunas de las obras más representativas de Winckelmann, además de las ya citadas, son las siguientes: Sendschreiben von den Herculanischen Entdeckungen (1762), Anmerkungen über die Baukunst der alten Tempel zur Girgenti in Sizilien (1762), Geschichte 
gicos, para el estudio de la historia del arte de las antigüedades griega y romana que dominaron por completo la visión artística y estilistica de la belleza. Winckelmann poseia todos los conocimientos históricos, artísticos y estéticos de su tiempo pero su concepto de belleza estuvo supeditado a una serie de obras de arte que respondian a sus propios cánones de la contemplación directa, de las divisiones estilísticas y de la importancia de la escultura sobre la pintura. Esto último queda patente en la obra citada, en la que con su método innovador describe grandes esculturas, por todos conocidas, como el Apolo Belvedere o el Laooconte. Esta y otras obras entre las que destaca Monumenti antichi inediti (1767) son el resultado de sus numerosas estancias en Italia. Llegó en el año 1756 subvencionado por la corte de Dresde y allí realizó diferentes tareas entre las que cabe destacar las de bibliotecario del cardenal Archinto, conservador del Museo de Antigüedades de Albani y presidente de la Comisión de Antigüedades. Tanto la obra como la personalidad de Winckelmann trascendieron más allá de su generación. Asi por ejemplo, Herder fue uno de sus más aventajados alumnos y también en la obra de Goethe aparece claramente su influencia ${ }^{7}$. Para personajes tan relevantes como estos, Winckelmann era "un griego antiguo que el azar hizo nacer en la Alemania del siglo XVIII, pero cuya verdadera patria era la Atenas de Pericles". $Y$ asi se entiende que este personaje creyese que el hombre moderno sólo podría ser grande si imitaba a los antiguos. En el fondo, el pensamiento academicista de Winckelmann, podria preconizar la teoria clasicista de la belleza ideal. Los criterios de este erudito quedaron muy

der Kunst des Altertums (1764) (existe traducción castellana en Ed. Iberia, Barcelona, 1984), Monumenti antichi inediti (1767).

7 Herder en su obra Auch eine Philosophie der Geschichte zur Bildung der Menschheit (1774) expone su nueva visión de la historia, ya no cree en la idea del desarrollo, ni en que el momento en el cual se vive sea el más importante. Oriente, Egipto, Fenicia, Grecia, Roma, la Edad Media, etc. se le aparecen como etapas de crecimiento de la cultura. En su obra Plastik (1778) desarrolló sus ideas sobre la estética y en Kalligone (1800) ataca directamente la estética helénico-clásica de Schiller y Goethe. Por su parte Goethe vivía repartido entre dos mundos, el Norte y el Sur, y así lo explica J. ORTEGa y GaSSET en su obra Triptico. Goethe desde dentro, Espasa-Calpe, Col. Austral, Madrid, 1972, págs. 160-161: «Pero de tal modo nada contra la corriente de su vocación, que acaba por no saber hacer nada desde sí mismo. Para crear, necesita previamente imaginarse otro que el que es: un griego, un persa - pucheros, vasijas-. Porque éstas son las fugas más sutiles, pero más significativas, de Goethe: su fuga al Olimpo, su fuga al Oriente. No puede crear desde su yo irrevocable, desde su Alemania." Todo el arte que encontró en Italia y, especialmente en Roma, en las estatuas griegas, le llevaron a su visión clásica de la naturaleza, que debía coincidir con las leyes de ésta. Römische Eligien es el resumen de su sentir por Italia. En Achilleis (1799) adoptó el estilo y el lenguaje de Homero y en su ensayo Winckelmann und sein Jahrhundert (1805) definió lo clásico como lo más perfecto que se puede crear en la tierra. 
enraizados, por lo que ha sido siempre considerado como el padre de la arqueología clásica y el primer alemán historiador del arte. A través de esta novedosa ciencia creada por él, busca un nuevo sentido a la vida. Su pasión por los héroes de la llíada y por los platónicos puede ser tenida en cuenta como una fuerza dinámica del nuevo espíritu clásico.

Sin embargo, este interés por el mundo clásico no se desarrolló únicamente en países como Alemania e Italia, sino también en otros como Inglaterra. Por ejemplo E. Gibbon (1737-1794), paralelamente, tras profundizar y estudiar los sistemas políticos, en su obra Historia de la decadencia y caída del Imperio Romano (1776-1788), trató el final del mundo romano desde el punto de vista de la decadencia de Roma. El análisis de la historia religiosa y profana le llevó a la idea, incluso escandalosa en aquel momento, de que el cristianismo era el máximo responsable de la caída del mundo romano. Se trataba de un desafío que tanto E. Gibbon como los representantes de la "Aufklärung" debian afrontar ${ }^{8}$.

Otros autores como Jacob Burckhardt (1818-1897), intentaron unir la historia cultural y la historia del arte, ofreciendo una historia de la cultura. La forma magistral en el tratamiento se debió a la perfecta concepción metodológica de Burckhardt, que partiendo de unas ideas sustanciales podía llegar al espiritu del hombre y crear así una ciencia que lo estudie. Esta tendencia queda muy bien reflejada en la lectura de su obra La cultura del renacimiento en Italia (1860). En ella faltan el análisis de los aspectos económicos, religiosos y sociales, ausencia que por otra parte se detecta por regla general en todos los historicistas. Este estudio fue superado en parte cuando en 1959, A. Chastel publicó su Art et humanisme à Florence au temps de Laurent le Magnifique. Entre los trabajos más conocidos de Burckhardt destacan: Cicerone (1855), recopilación exhaustiva a modo de guía, que recoge el arte italiano de la antigüedad, catalogando las obras arquitectónicas, escultóricas y pictóricas tanto por períodos como por regiones. También cabe mencionar las grandes empresas de dicho autor, como son: Del paganismo al cristianismo. La época de Constantino el Grande (1853) e Historia de la cultura griega $(1898-1902)^{9}$. Es probablemente Jacob Burckhardt uno de los teóricos

${ }^{8}$ A. Burguiére: Dictionnaire..., citado, voz: Gibbon, págs. 305-306. H. I. Marrou: De la connaissance historique, Editions du Seuil, Col. "Points Histoire», Paris, 1975, pág. 269.

9 A. Burguiere: Dictionnaire..., citado, voz: Burckhardt, págs. 101-102. En lodos los volúmenes historiográficos, tanto artísticos como arqueológicos, aparecen comentarios abundantes sobre este autor, asi cómo en todas las traducciones, véase por ejemplo: $F$. CHECA, et alii: Guía para el estudio de la historia del arte, citado, págs. 97-98; J. Viñuales. El comentario..., citado, págs. $28-34$ y 247. 
que más influyó en las investigaciones posteriores tanto desde un punto arqueológico como histórico del arte, pero quizás ejerció un mayor impacto en este último campo, incluso hasta fechas muy recientes.

Hemos visto como estos teóricos se preocuparon por la historia del arte, pero como veremos más adelante, sólo Aloïs Riegl hizo los primeros intentos por demostrar cómo arqueología y arte no pueden ir desligados.

Los criterios winckelmanianos sobre la historia del arte y la arqueología de la antigüedad, consideradas éstas como el reflejo de una distinción social elitista sensibilizadora de los individuos cultivados de la época, quedaron sumamente arraigados. Por ejemplo la teoría de E. Gibbon y algunas de las ideas de $\mathrm{J}$. J. Winckelmann no fueron reestudiadas hasta Aloìs Riegl, aunque con un tratamiento diferente, en el siglo XIX, período durante el cual aparecerán interesantísimas figuras para el estudio del campo que nos ocupa, tanto de historiadores del arte como de arqueólogos. Es la época de la búsqueda y explosión de conceptos e ideas, que definirán las múltiples, variadas y - por qué no- enfrentadas escuelas del siglo xx. También es el momento del complejo ensamblaje entre la discusión de las cuestiones epistemológicas y la automatización de la historia del arte, y para su entendimiento es necesario conocer a Aloïs Riegl.

Aloïs Riegl (1858-1905), de origen austríaco, con una formación de jurista, pero con amplísimos conocimientos en filosofía e historia, estuvo destinado a ocupar tres puestos de vital importancia - a pesar de haber muerto muy joven, a los 47 años - para el progreso científico de su país. A partir de 1886, el de conservador en la sección de artes textiles del Museo de Artes Decorativas de Viena. Al mismo tiempo se dedica a la docencia universitaria, hasta que en 1897, obtuvo el grado de catedrático. Cinco años más tarde es nombrado presidente de la Comisión Central Imperial y Real de Monumentos Históricos y Artísticos. Toda su argumentación ${ }^{10}$, se basa en la teoría del "kunstwollen" o voluntad del arte, donde todo producto artístico, línea o color, volumen o espacio, es el resultado de una intención muy precisa. Por tanto este "kunstwollen» se orienta de forma consciente y se contrapone a la finalidad de uso, tanto material como técnica. Los primeros titubeos de este formalismo

${ }^{10}$ En prácticamente todas las historiografías de la historia del arte, así como en las introducciones a las traducciones de las obras se encuentran amplios comentarios sobre este investigador. Sin embargo resulta de primordial importancia consultar un volumen dedicado a la vida y obra de A. Riegl; véase S. ScarrocchiA: Studi su Alois Riegl, Istituto per I Beni Culturali, Artistici e Naturali della Regione Emilia-Romagna, Edit. Nova Alfa, Emilia Romagna, 1986. 
estético lo llevaron a escribir varias obras fundamentales. Su libro industria artística tardorromana (1901) ${ }^{11}$ refleja que el material artístico-arqueológico es para él el mejor modo de ejemplificar todo un tejido mental, y para demostrarlo, Riegl, estudió una serie de objetos de artes menores del período de la antigüedad tardía, hasta entonces olvidados por completo, tratando dichos objetos no como decadentes sino precisamente como elementos de progreso o de perfeccionamiento de los valores autónomos. Se pone así de manifiesto el concepto igualitario de Riegl para todas las manifestaciones artísticas, ya sean aquellas consideradas "artes mayores" como las "artes menores", olvidando de este modo las concepciones tradicionalistas sobre la estética intelectual o sensual de, por ejemplo, las esculturas del mundo clásico. En la obra ya citada, Industria artística tardorromana, Riegl consiguió demostrar cómo a partir del estudio de pequeños objetos - a simple vista poco informativos- se podía llegar a conocer todo un proceso mental, o lo que es lo mismo para él, una voluntad artística que esconde, como decíamos más arriba, una intencionalidad canalizada. Con esta obra y la Escuela de Viena, nace pues el concepto de antigüedad tardia, que Aloïs Riegl esbozó y que mucho más tarde Henri-Irenée Marrou desarrolló y divulgó de forma magistral ${ }^{12}$. La otra, corta pero gran obra de Riegl y que demuestra sus profundos conocimientos de la historia del arte, que podríamos denominar “monumental» es El culto moderno a los monumentos (1903). En ella se lee claramente su teoría de que la configuración artística reside en los valores de lo táctil y lo óptico, y dice exactamente así: "Según la definición más usual, obra de arte es toda obra humana apreciable por el tacto, la vista o el oído que muestra un valor artístico, y monumento histórico es toda y cada una de estas obras que posee un valor histórico.

11 Además de esta obra cuyo título original es Spätrömische Kunstindustrie nach den Funden in Oesterreich und Ungarn, destacan también: Stilfragen (1893) (traducción castellana con el título Problemas de estilo. Fundamentos para una hisotria de la ornamentación, Ed. G. Gili, Barcelona, 1980), Das holländische Gruppenportrait (1902), Der moderne Denkmalkultus. Sein Wesen und seine Entstehung (1903). Después de su muerte fueron publicadas otras obras que eran básicamente los apuntes de los cursos pronunciados en la Universidad de Viena: A. BuRDA y M. Dvorak, édit.: Die Entstehung der Barockkunst in Rom, 1908; E. H. ZimmERMANN, Edit: Kunstgewerbe des frühen Mittelalters, 1923, y K. M. SwoBOda y O. PACHT: Historische Grammatik der Bildenden Künste, 1966. Entre los varios artículos de Riegl que fueron recogidos por A. SEDLMayen, édit.: Gesammelte Aufsätze, Augsburg-Viena 1929, destaca uno sobre el origen de la basílica, que cabe citar aqui pues entra bien en la dialéctica iniciada por este autor con respecto a la antigüedad tardía: “Zur Entstehung der altchristlichen Basilika", Jahrbuch der K. K. Zentralkommission, N.F., 1, 1903, págs. 195-216.

12 H. I. MarRou: Décadence romaine ou antiquité tardive?, Ed. du Seuil, Col. "Points Histoire", Paris, 1977. Existe una traducción al castellano de Ed. Rialp, Madrid, 1980. 
En nuestro contexto, podemos excluir de nuestra consideración, desde un principio, los monumentos perceptibles por el oído (musicales), ya que, en lo que aquí nos puede interesar, han de ser incluidos entre los monumentos históricos. Por tanto hemos de preguntar exclusivamente con relación a las obras perceptibles al tacto y a la vista de las artes plásticas (en el sentido más amplio, es decir, abarcando toda creación de la mano humana): ¿Qué es valor artístico y qué es valor histórico?»13. Su óptica formalista, tanto en el campo de la historia del arte y de la arqueología, que unió en un único sistema de análisis, contrasta con la de sus predecesores y contemporáneos.

A su vez, Theodor Mommsen (1817-1903) en su Historia de Roma (1854-1856) se esforzó por llevar a cabo una historia global de la antigüedad romana, combinando las diferentes disciplinas, hasta entonces independientes unas de otras (derecho, filología, literatura, arqueología, epigrafía, etc.) aunque esta nueva interpretación de la historia no tuvo eco - y de forma muy diferente - hasta la década de los años setenta del presente siglo. Mommsen fue más allá del «realismo crítico", aplicando un gran rigor metodológico; y así lo expresó el Secretario de la Academia Sueca, al serle otorgado el Premio Nobel de Literatura en 1902: “En Mommsen se da una notable coincidencia de condiciones personales, en otro caso antitéticas. $\mathrm{Si}$, por una parte, es un sesudo investigador, un infatigable explorador de fuentes, por otra parte es capaz a veces de un franco apasionamiento al enjuiciar; junto a la asombrosa erudición que le permite sumergirse sin desorientarse en las más recónditas interioridades de la maquinaria estatal o en los entresijos laberínticos de la vida económica, tiene una prodigiosa capacidad visual para reproducir con rasgos fieles y deslumbrantes al panorama de una batalla - la fisonomía de un gran personaje. Acaso es, por encima de todo, un artista, y su Historia de Roma una gigantesca obra de arte" ${ }^{14}$. Efectivamente Mommsen era un erudito cuyas obras sobre fuentes escritas de la antigüedad son un útil imprescindible, pero cuya influencia en el campo de la historia del arte fue mínima.

Más adelante y siempre en el ámbito de la historia del arte, el francés Henri Focillon (1881-1943) defiende la vida autónoma de las formas. Las diversas fases de metamorfósis sufridas por la forma conducen a las

13 A. RIEGL: Der moderne Denkmalkultus. Sein Wesen und seine Entstehung, Viena Leipzig, 1903, traducción al castellano en Ed. Visor, Madrid, 1987, págs. 23-24.

${ }_{14}$ T. Mommsen: Römische Geschichte, 1855-1856 (utilizamos la edicion española, Historia de Roma, Madrid, 1965. Cfr. el discurso del Secretario C.D. af Wirsen, pág. 16). 
obras a evolucionar así bien en el espacio que en el tiempo ${ }^{15}$. La escuela formalista de Focillon se opuso drásticamente, después de la última guerra, a la de la sociología del arte propuesta por Pierre Francastel, de donde surge la actual historiografía sociológica del arte cuya teoria fue expresada básicamente en su libro Sociología del Arte de $1970{ }^{16}$, que se contrapone a la vez, a la Historia social de la literatura y del arte (1969) de Arnold Hauser. La lectura de los manuales de este último, aunque éstos no se puedan considerar vigentes, aún se recomienda en los circulos universitarios, y no precisamente con el sentido historiográfico que podria desearse.

Otro formalista y gran historiador del arte que ha marcado profundamente muchas generaciones actuales de investigadores es Heinrich Wölfflin (1864-1945) ${ }^{17}$. En su obra Conceptos fundamentales de la Historia del Arte (1915), optó por considerar que es la forma la que organiza y da sentido a la obra de arte, es decir es la fuerza activa la que estructura el arte. Siendo así, la forma óptica la que da unidad a la obra, ésta le permitió paralelizar hasta extremos insospechables el arte antiguo con el arte de su época. La claridad y sencillez en el momento de exponer su teoría le proporcionaron una gran difusión, incluso llegando más allá de los especialistas e investigadores, por lo que sus obras son leídas como manuales actuales en las universidades, a pesar de que las tendencias han variado.

Pero, paralelamente a este campo erudito del saber del siglo XIX, existieron verdaderas revoluciones. Por un lado la explosión de los nacionalismos y regionalismos que utilizaron - a veces con motivo y otras sin razón- la arqueología como base de sus argumentos políticos. Es bien sabido que no existe ciencia - y menos aún ciencia histórica- sin ideología. Por otro lado, y con un peso bastante considerable y ventajoso, se van reafirmando las instituciones con verdadero carácter aqueológico. Así por ejemplo la "Commision des Monuments Historiques", fundada en

${ }^{15}$ A. Burguiere: Dictionnaire..., citado, voz: Focillon, págs. 289-290. H. Foc!llon: La vie des Formes, 1934, existe traducción castellana, Buenos Aires, 1947. Véase también los apuntes que da J. VinuAl.ES: El comentario..., citado, págs. 58-59.

${ }^{16}$ Francastel al igual que Focillon tiene una numerosisima obra, entre la que cabe destacar: Art et téchnique. La genèse des formes modernes. Paris, 1956. De su obra de mayor trascendencia, Sociología del arte (1970), existe una traducción castellana en Alianza Ed., Madrid, 1975.

17 La obras más importantes de Heinrich WOLfFLIN son: Renaissance und Barock (1888) (traducción castellana en Ed. Comunicación, 1971), Die klassische Kunst (1899), Kunstgeschichtliche Grundbegriffe (1915) (traducción castellana en Ed. Espasa-Calpe, Madrid, 1961) y Italien und das deutsche Formgefühl (1931). 
Paris en 1870 , tiene en este momento un papel muy representativo, pues se están separando las diferentes arqueologías y a la vez descubriendo hasta que punto la Edad Media y sus monumentos tienen una importancia dentro de la historia de cada país. Todos estos fenómenos aunados, hacen que la arqueología y la historia del arte, en casos como es el de la Edad Media en Francia, tenga ya una muy larga y consolidada tradición, llena de escuelas y personalidades cuya discusión científica hace avanzar a grandes pasos tanto esta historia del arte como la propia arqueología medieval ${ }^{18}$. En España, por ejemplo, ya desde mediados del siglo XIX, tanto la "Comisión de Monumentos Arquitectónicos de España" (1856), como la "Real Academia de la Historia» creada con anterioridad (1735), toman la iniciativa de controlar, proteger y excavar, monumentos y yacimientos arqueológicos de todas las épocas. Recordemos algunos ejemplos relevantes: el arqueológo e historiador José Amador de los Rios y el descubrimiento del Tesoro de Guarrazar (Toledo), tan fatalmente perdido y distribuido por los museos; o también y de época anterior la seria investigación de Joseph Córnide en las ruinas romanas e iglesia visigoda de Segóbriga (Cuenca). La creación del "Institut d'Estudis Catalans" (1907), como principal órgano canalizador de la ciencia catalana, es un ejemplo evidente de la labor que se estaba llevando a cabo desde finales del siglo XIX y principios del XX. Uno de sus máximos representantes, Josep Puig i Cadafalch, básicamente arquitecto de formación, pero también arqueólogo, historiador del arte y político, fue el encargado de excavar la entonces recientemente revalorizada ciudad grecorromana de Ampurias ${ }^{19}$ y es un ejemplo claro de la búsqueda de nuevas soluciones a una conjunción entre la historia del arte y la arqueologia de la antigüedad y la Edad Media.

Pero la verdadera definición teórica de lo que es la arqueología, no existe todavia, y no aparecerá hasta mediados del siglo $\mathrm{xx}$. Esta definición no puede ser comprendida sin analizar uno de los fenómenos históricos más importantes para lo que es la historia de la historia. Nos

${ }^{18}$ Algunas sugerencias sobre los problemas franceses en: A. LAMING-EMPERAIRE: Origines de l'Archéologie Préhistorique en France, Paris, 1964. También en: C. DE BellegardeBARRAL: Les "Mérovingiens" au sein des premières institutions archéologiques nationales (1830-1848), Archéologie Aujourd'hui, n. 2 (Les mérovingiens. Archéologie et Historiographie), Paris, 1989 , págs. 16-22.

${ }^{19}$ E. Ripoll Perello: Josep Puig i Cadafalch i les excavacions d'Empúries, Institut de Prehistoria i Arqueología, Patronat de les Excavacions i Museu d'Empùries de les diputacions de Barcelona i Girona, Barcelona, 1977. Para la biografía de J. Puig i Cadafalch remitimos al libro de E. JARDI: Puig i Cadafalch, arquitecte, polític i historiador de l'art, Caixa d'Estalvis Laietana, Mataró, 1975. Véase también la publicación L'Institut d'Estudis Catalans, 1907-1986, Barcelona, 1986, 29 págs. 
referimos a la Escuela de los Annales ${ }^{20}$, que tomó cuerpo entre los años 1920 y 1930 de la mano de Marc Bloch y Lucien Febvre, a la que se vincularon después estrechamente Georges Lefebvre, Fernand Braudel, Georges Duby, Jacques Le Goff, etc., aunque algunos de ellos de forma distinta, al surgir nuevos temas de estudio y nuevos enfoques a los ya existentes. La Escuela de los Annales creó el concepto de la historia de la idea, asi como el de la historia de las mentalidades, es decir el estudio interdisciplinar y multifacético dentro de las ciencias sociales, de un fenómeno histórico, económico y social. La Escuela de los Annales siguió sus conceptos iniciales de historia no automática sino problemática, mientras Bloch y Lefebvre los defendieron, pero las nuevas corrientes modificaron en cierto modo su orientación, y muchos estudiosos de dicha escuela se decantaron hacia la "nueva historia", cuya verdadera dimensión se alcanzará a partir de los años $1970^{21}$, con lo que se ha dado en denominar "l'histoire à longue durée», de difícil traducción (historia no compartimentada o de grandes ciclos).

Durante toda la primera mitad del presente siglo, la arqueología sigue su desarrollo normal como "arqueología de campo", "arqueología tradicional" y "arqueología de museo", que da lugar a nuevos descubrimientos de mayor o menor envergadura, realizándose como complemento inventarios, catálogos y algunos intentos de síntesis, con -a veces- una gran falta metodológica pues fundamentalmente no se plantean los problemas de definición y los objetivos que se persiguen con este tipo de trabajos. Este momento podría ser definido como el periodo de la "arqueología del corpus", pues se están publicando los catálogos de casi todos los museos europeos y de todas las colecciones, tanto arqueológicas como pictóricas, tal como había preconizado ya Mommsen ${ }^{22}$. No dejan de tener su lado meritorio pues ofrecen una abun-

20 Sobre la escuela de los Annales existen abundantes alusiones en prácticamente todos los manuales. Véase particularmente el capitulo de J. LE GoFF: "L'histoire nouvelle", en La nouvelle histoire, Paris, 1978 (reedicción aumentada, 1988), págs. 35-76.

${ }_{21}$ Entre la obras más recientes cabe destacar el volumen recientemente reeditado y citado anteriormente, J. LE Goff, et alii: La nouvelle histoire, Paris, 1988. En él se recogen varios capítulos realizados por autores diferentes y sobre las diversas áreas de la historia. Véase también aunque de época anterior, los volúmenes recapitulativos sobre esta problemática: J. LE Goff y P. NorA (edit.): Faire de l'histoire. I, Nouveaux problèmes. II, Nouvelles approches. III, Nouveaux objets, París, 1974. Existe una traducción al castellano en 2 vols. de Ed. Laya, Barcelona, 1984 (nosotros utilizamos la versión francesa).

22 T. MOMmSEN: Corpus Inscriptionum Latinarum, 1863. Salomon Reinach es uno de los más grandes eruditos que empezaron a realizar los corpora, por ejemplo: Réperioire de la statuaire grecque et romaine, Paris, 1897-1898; Repertoire des vases grecques et étrusques, Paris, 1899; Répertoire des peintures du Moyen Age et de la Rénaissance, 1-III, Paris, 
dantísima documentación científica prácticamente desconocida y muchas veces hoy irrecuperable. Recordemos que son los peores momentos del nazismo, franquismo y fascismo, que tanto perjudicaron a la ciencia. En Alemania, por ejemplo, muchos arqueólogos, y sobre todo prehistoriadores, participaron activamente en la política cultural nazi. Amparándose en instituciones como "Kampfbund für deutsche Kultur" (Liga de combate por la cultura alemana), llegaron a la convicción de pertenecer a un país cuya cultura eclipsaba a las otras. Pero la responsabilidad colectiva de los universitarios alemanes en el proceso de corrupción quizás pueda verse atenuada por la ausencia de solidaridad crítica internacional ya que paises como Francia, Italia y España también concurrieron en esta idea de la «banalidad del mal» ${ }^{23}$.

Los verdaderos progresos cientíicos en arqueología llegarán a mediados del siglo $x x$, frente a la solidez que tienen ya desde la década de los años treinta los estudios históricos gracias a la dialéctica establecida por la Escuela de los Annales. Por ejemplo en España, son pocos los investigadores preocupados por una correcta definición de la arqueología, pero, como excepción, quizás valga la pena resaltar al ilustre Antonio García y Bellido ${ }^{24}$, que más que la unión entre historia del arte y la arqueología, lo que intentó fue aunar el método del historiador de la antigüedad con el método arqueológico, y éste es un fenómeno importante y a la vez laudable, si tenemos en cuenta que todavia hoy muchos arqueólogos no utilizan las fuentes antiguas con el debido rigor. Quizás debamos también resaltar el caso especial de la investigación hispánica, con una larga tradición en la ciencia prehistórica, pero no tan acentuada en la arqueología clásica. Probablemente es este un elemento a tener

1905-1910; Repertoire de reliefs grecques et romains, I-III, Paris, 1909-1912. Entre otros, y tan sólo a modo de ejemplo resaltan también los siguientes autores: P. PARIS: Essai sur l'art et lindustrie de l'Espagne primitive. 2 vols., Paris, 1904-1905; Id., Le Musée archéologique national de Madrid, Paris, 1936; F. Álvarez Ossorio: Catálogo de los exvotos de bronce ibéricos, 2 vols., Madrid, 1941. También destacan, los siguiente volumenes coeditados conjuntamente por el Institut d'Estudis Catalans y la Union Académique Internationale: Corpus Vasorum Antiquorum, el Corpus Vitrearum Medii Aevi, etc.

23 A. SCHNAPP: “Archéologie et nazisme”, Quaderni di Storia, 5, Bari, 1977, págs. 1-27. Artículo con abundante bibliografia sobre esta problemática.

${ }^{24}$ La obra de A. GARCIA Y BELLIDO es amplísima, pero para el estudio que nos concierne es muy ilustrativo el volumen: Arte romano, Enciclopedia Clásica n. ${ }^{\circ}$, CSIC, Madrid, 1972 (2. ${ }^{a}$ edición ampliada). También: España y los españoles hace dos mil años según la geografia de Strabón, Madrid, 1945; La España del siglo primero de nuestra Era, según P. Mela y C. Plinio, Madrid, 1947; Veinticinco estampadas de la España antigua, Madrid, 1967. Véase igualmente : E. RIPOLL Perelló: "Profesor don Antonio García y Bellido (19031972)", Información Arqueológica, II, Barcelona, 1972-1973, págs. 94-95. 
muy en cuenta cuando intentamos entender el progreso unitario de una historia del arte y una arqueologia.

Por otro lado no podemos olvidar el desarrollo de la ciencia arqueológica europea de los años cincuenta, donde el investigador italiano Nino Lamboglia jugó un importante papel ${ }^{25}$. Inspirándose en los métodos de excavación estratigráfica de los prehistoriadores y apurando las tipologías cerámicas, deslumbró a muchos arqueólogos de la cuenca mediterránea que buscaban nuevas vias de investigación en la interpretación de la compleja cultura material. El método Lamboglia, que aunque había sido creado para ser utilizado en unos yacimientos muy concretos, fue aplicado a veces incorrectamente en otros, y por ello durante unas décadas muchos arqueólogos del Mediterráneo occidental vivian obsesionados por los fragmentos cerámicos con el fin de analizar unas clases sociales determinadas, sumándose a todo ello la proliferación de estudios estadísticos y sus representaciones gráficas. Se huía de una arqueología que podriamos definir «de la aristocracia» o “de la nobleza», para conocer - se creía a través de la cerámica - las clases más bajas de la sociedad. Lo mismo había ocurrido con la historia del arte, que se consideraba un estudio aristocrático de lo bello y como un estudio de la creación artística y artesana del hombre. El método lambogliano, válido si se utiliza correctamente, no tuvo una buena aplicación y unos buenos resultados hasta bastantes años más tarde. Hay que tener en cuenta que toda la información dada por un objeto es absolutamente parcial y se halla fuera de su contexto inicial, por tanto su interpretación será siempre subjetiva, según el investigador que la estudie ${ }^{26}$. Así por ejemplo las clasificaciones tipológicas -tanto estilísticas como cronológicas-, las estadísticas, etcétera, sumadas a una absoluta preocupación por el método y no tanto por los resultados obtenidos, nos ofrecen una realidad parcial, que no nos permite conocer la totalidad del pasado, e incluso puede llegar a esconder respuestas vitales, para el conocimiento de la vida y las mani-

${ }^{25}$ Véanse los artículos más significativos para su propuesta: N. LAMBOGLIA: "Per una classificazione preliminare della ceramica campaña", $l^{\circ}$ Congresso Internazionale di Studi Liguri, 1950, Bordighera, 1952, págs. 139-206; Id.: "Nuove osservazioni sulla "Terra Sigillata Chiara", II, (Tipi A e B)", Rivista di Studi Liguri, XXIV, 1958, págs. 257-330; Id.: "Nouve osservazioni sulla 'Terra Sigillata Chiara', II, (Tipi C. Lucente e D)", Rivista di Studi Liguri, XXIX, 1963, págs. 145-212, Véase tambièn el texto de E. RIPOLL PERELL: “Muerte del Profesor Nino Lamboglia», Información Arqueológica, IV, Barcelona, 1976-1977, pág. 150.

${ }_{26}$ Muy interesantes son las consideraciones hechas por el Prof. Grimal sobre éste y otros problemas. Véase la entrevista realizada por G. RIPOLL: «Pierre Grimal. Donner un sens à l'histoire", Archéologia, n. ${ }^{\circ} 213$, Dijon, 1986, págs. 17-21. 
festaciones del hombre. Entramos entonces en el terreno siempre ambiguo y resbaladizo de las suposiciones.

Quizás el gran ideólogo de una nueva visión donde la historia del arte y la arqueología formasen parte de los mismos presupuestos cientificos fue Ranuccio Bianchi Bandinelli, cuyas relaciones con el movimiento alemán son indiscutibles ${ }^{27}$. Mucho se ha evolucionado desde Winckelmann y Riegl hasta Bianchi Bandinelli, y a este último se deben los grandes volúmenes de síntesis y las indicaciones de los caminos a seguir a partir de entonces, en lo que es la historiografía artística. El mismo definía en el prólogo a su Introducción a la Arqueología el devenir de estas ciencias que nos ocupan: "Los historiadores del arte de la antigüedad representan hoy, sin duda, una fauna en vías de extinción, a pesar de que casi todos los arqueólogos clásicos se ocupan de materiales que tienen forma artística; pero estudiar un objeto artístico para extraer de él un dato cronológico o histórico no es hacer historia del arte. No puedo dejar de considerar lamentable tal circunstancia, porque en realidad apenas se había empezado a alcanzar una comprensión crítica y efectivamente histórica del arte del área helénica y de la época romana, y el verdadero problema sigue estando aún por afrontar y desarrollar". Su personalidad y sus obras, sumadas a la revolución cultural y social del mayo de 1968, representan el final de la fisura ideológica entre dos ciencias, la historia del arte y la arqueología, para convertirlas en una única historia. La fisura generada por la revolución antes mencionada, en la que todos hemos participado de forma directa o indirecta, está marcada por un debate tanto político como teórico que ha permitido a la vez un rapidísimo desarrollo de este proceso de unión entre historia del arte y arqueología. Este proceso viene acompañado de los grandes movimientos intelectuales de esos años, surgen los "nuevos filósofos", definitivamente la «nueva historia», etcétera, como oposición a un sistema investigador y a un pensamiento tradicional, que no tenían ya salida. Se inten-

${ }^{27}$ En el volumen de A. CARANDIni: Arqueología y cultura material, Ed. Mitre, Barcelona, 1984 , donde se recogen varios artículos de diferentes épocas del autor, en él se incluye un extenso capitulo sobre el que fue su maestro R. Bianchi, haciendo un tratamiento crítico de su obra e ideología. Por otra parte es imprescindible recurrir a los propios libros de Bianchi, entre los que destacan entre otros los siguientes: R. BIANCHI BANDINELLI: Archeologia $e$ cultura, Milán-Nápoles, 1961; Id., L'arte romana al centro del potere, Milán, 1969; Id., Roma. La fine dell'arte antica, Milán, 1970 (de ambos volúmenes existen traducciones castellanas en "el Universo de las Formas" publicado por Ed. Aguilar); Id. y A. Giuliano, Etruschi e Italia prima del dominio di Roma, Milán, 1973. Véase también la antes citada Introducción a la arqueologia, 1976 (1982) y su obra póstuma Del helenismo a la Edad Media, Edit. Akal, Madrid, 1981. Para conocer el pensamiento político de este autor debe consultarse su propio diario, Dal diario d'un borghese e altri scritti, Roma, 1962 (1976). 
taba dilucidar lo que era verdaderamente la arqueología, se pusieron en duda todos los presupuestos teóricos de ésta ${ }^{28}$ y se quiso crear -en la medida de lo posible - una "nueva arqueología", basada en el instrumentum domesticum o en la cultura material, teoría del investigador italiano Andrea Carandini ${ }^{29}$, filtrada y derivada de la labor pionera de $\mathrm{N}$. Lamboglia. El apelativo "cultura material» se debe a la creación por parte de Lenin en 1919 de la "Academia de historia y de la cultura material de la URSS" ${ }^{30}$, y fue recuperado por dichos investigadores, el primero R. Bianchi Bandinelli, durante este periodo. Las experiencias del arqueólogo Andrea Carandini, sobre todo en Settefinestre y en la gran villa romana de Piazza Armerina, en Italia, han demostrado que utilizando, aplicando y razonando con unos buenos métodos arqueológicos se puede llegar a sintesis de alto nivel sin ser parcelarias científicamente, sino que alcanzan todas las estructuras, manifestaciones e ideologias sociales. Se empieza así a discernir, a finales de los años sesenta, entre lo que es la aplicación de un "método" puramente arqueológico y lo que es un "razonamiento» arqueológico. Por otra parte, en historia del arte se sustituyen los conceptos de estructura, composición, etcétera, por el de “campo", básicamente campo iconológico.

Con la revolución del mayo del 68 se reafirmaron o nacieron nuevas áreas de investigación arqueológica: la medieval, la industrial e incluso la del mañana. Estas nuevas arqueologias tienden a ser interdisciplinarias con un marco cultural muy amplio y una visión que podríamos calificar de humanista pero que no olvida en ningún momento el método científico. Se alcanza de este modo la simbiósis de la historia del arte y de la arqueologia, para llegar asi a un profundo conocimiento de la historia social, económica, artística, cultural, etcétera, que hasta el momento había sido realizada independientemente por especialistas de cada campo.

Hasta el momento hemos visto la evolución, digamos historiográfica, de los conceptos que nos proponiamos plantear, los de arqueología e

28 Además de las obras de G. Daniel, V. Gordon Childe y B. G. Trigger, citadas en la nota 3, junto a los volúmenes de $\mathrm{R}$. Bianchi Bandinelli y A. Carandini, y los artículos recogidos en Faire de l'histoire (cf. nota 21) resultan de interés P. CourbIN: Que'est-ce que l'archéologie? Essai sur la nature de la recherche archéologique, Paris, 1982; S. TABACYNSKY: "Tradizione positivista e "Nouva archeologia"", Archeologia medievale, XI, Florencia, 1984, págs. 7-33, I. HoDoER: Interpretación en arqueologia. Corrientes actuales, 1986 (edición española en Ed. Crítica, Barcelona, 1988).

${ }^{29}$ A. CARANDINI: Arqueología y cultura material, citado. Es el volumen donde se reúne básicamente todo el pensamiento de dicho investigador, además de contener una amplia bibliografía a la que remitimos.

${ }^{30}$ De gran utilidad es el capitulo dedicado a este tema de J. M. PESEZ: “Histoire de la culture materielle", en J. LE GoFf: La nouvelle histoire, citado, págs. 190-227. 
historia del arte antiguo y medieval, sin embargo queda todavía por resolver una cuestión de difícil solución. ¿Cuáles son actualmente los puntos imprescindibles y directorios de la investigación? Sin lugar a dudas, los conceptos de historia del arte y arqueología siguen existiendo - pero creemos que podemos afirmar con bastante fiabilidad - con una perspectiva integradora que trabaja a favor de la shistoria total" ${ }^{31}$. Historia total entendida como estudio de un fenómeno que será analizado a lo largo de un vasto período y por medio de todas las ciencias (que es lo que inició la Escuela de los Annales) cuya dimensión esencial es la de lo imaginario. El origen de esta historia total debemos buscarlo en la "nueva historia" a la que nos referíamos anteriormente, al frente de la cual se encuentran investigadores y teóricos de la talla de Fernand Braudel ${ }^{32}$, Jacques Le Goff ${ }^{33}$ o Georges Duby ${ }^{34}$. Todos ellos influidos por la corriente conocida con el nombre de historia de las mentalidades, pero al mismo tiempo por el estructuralismo de Levi-Strauss, por el marxismo y por la antropologia histórica; y sintiendo sus deficiencias en el momento de "hacer Historia", se dedican al estudio profundo y meditado, huyendo de las sistematizaciones y del empirismo, y ayudándose para ello de todas las ciencias humanas, de la "metodologías itinerantes», de las ideologías sociales que son en definitiva todas las manifestaciones materiales y espirituales del hombre.

El futuro histórico de este largo camino, con amplios horizontes, que fue iniciado por Vasari, seguido por muchos otros, trabajado esencialmente por Winckelmann y Riegl, y defendido con gran cientifismo por otras figuras del siglo $x x$, está en manos de las nuevas y venideras generaciones de historiadores. En ellas queda el esfuerzo de crear o dirigir la historia, como dice Jacques Le Goff ${ }^{35}$, «hacia una ciencia global del hombre en el tiempo".

${ }^{31}$ Véanse básicamente las obras citadas en la nota 21 , y las de los autores pertenecientes a esta corriente y que hemos citado.

${ }^{32}$ F. Braudel: Ecrits sur l'histoire, Paris, 1969. Muy interesante resulta el volumen "Châteuvalion" sobre unas Jornadas dedicadas a Fernand Braudel en octubre de 1985 y que fueron publicadas con el título: Une leçon d'histoire de Fernand Braudel, Paris, 1986.

${ }^{33}$ Para conocer el pensamiento de Jacques Le Goff, es básico conocer su obra ya citada La nouvelle histoire, Paris, 1988 (se trata de una edición aumentada de la obra de 1978).

${ }^{34}$ Georges Duby es uno de los historiadores que más ha llegado a todos los públicos, por ello sus escritos son de fácil acceso, sin embargo es importante consultar un volumen donde se expone a modo de diálogo todo su pensamiento: G. DuBY y G. LARDREAU, Diálogo sobre la Historia, 1980 (versión española en Alianza Ed., Madrid, 1980).

${ }^{35}$ J. LE Goff, La nouvelle histoire, citado, pág. 65. 